\title{
Invaluable Role of Consanguinity in Providing Insight into Paediatric Endocrine Conditions: Lessons Learnt from Congenital Hyperinsulinism, Monogenic Diabetes, and Short Stature
}

\author{
Shenali Anne Amaratunga ${ }^{a}$ Tara Hussein Tayeb ${ }^{b}$ Petra Dusatkova ${ }^{a}$ \\ Stepanka Pruhova ${ }^{a}$ Jan Lebl ${ }^{a}$ \\ aDepartment of Paediatrics, 2nd Faculty of Medicine, Charles University in Prague, Prague, Czech Republic; \\ ${ }^{b}$ Department of Paediatrics, Sulaymani University, College of Medicine, Sulaymani, Iraq
}

\section{Keywords}

Novel genes - Genetic testing • Consanguineous families ·

Paediatric endocrinology · Endocrine genes

\begin{abstract}
Consanguineous families have often played a role in the discovery of novel genes, especially in paediatric endocrinology. At this time, it has been estimated that over $8.5 \%$ of all children worldwide have consanguineous parents. Consanguinity is linked to demographic, cultural, and religious practises and is more common in some areas around the world than others. In children with endocrine conditions from consanguineous families, there is a greater probability that a single-gene condition with autosomal recessive inheritance is causative. From 1966 and the first description of Laron syndrome, through the discovery of the first $K_{\text {ATP }}$ channel genes $A B C C 8$ and $K C N J 11$ causing congenital hyperinsulinism (CHI) in the 1990s, to recent discoveries of mutations in YIPF5 as the first cause of monogenic diabetes due to the disruption of the endoplasmic reticulum (ER)-to-Golgi trafficking in the $\beta$-cell and increased ER stress; positive genetic findings in children from consanguinity have been important in elucidating novel genes and mechanisms of disease, thereby ex-
\end{abstract}

panding knowledge into disease pathophysiology. The aim of this narrative review was to shed light on the lessons learned from consanguineous pedigrees with the help of 3 fundamental endocrine conditions that represent an evolving spectrum of pathophysiological complexity - from $\mathrm{CHI}$, a typically single-cell condition, to monogenic diabetes which presents with uniform biochemical parameters (hyperglycaemia and glycosuria), despite varying aetiologies, up to the genetic regulation of human growth - the most complex developmental phenomenon.

(c) 2021 The Author(s) Published by S. Karger AG, Basel

\section{Introduction}

Five per cent of all live births have genetic disorders that are recognizable until 25 years of age [1]. These genetic disorders are being increasingly diagnosed in the human population due to developments in genetic testing technology and tools such as next generation sequencing (NGS).

The knowledge on the genetic cause of disease allows precise and individualized clinical management, faster diagnosis without the need of invasive diagnostic tests (in karger@karger.com www.karger.com/hrp

Karger $\stackrel{\text { ' }}{5}$

BOPEN ACCESS
(C) 2021 The Author(s)

Published by S. Karger AG, Basel

This is an Open Access article licensed under the Creative Commons Attribution-NonCommercial-4.0 International License (CC BY-NC) (http://www.karger.com/Services/OpenAccessLicense), applicable to the online version of the article only. Usage and distribution for commercial purposes requires written permission.
Correspondence to:

Shenali Anne Amaratunga, shenali.amaratunga@fnmotol.cz 
some cases), prediction of long-term outcome and family planning. The decision on carrying out genetic examination is not only based on the potential therapeutic benefit, but on the feasibility, availability, and cost-effectiveness as well [2]. Prior to the indication of genetic testing, a comprehensive medical history should be obtained; this should include the presence of consanguinity in the family.

Due to the impact that paediatric endocrine disorders can have on a child's metabolism, electrolyte balance, and growth and development, they represent a substantial part of paediatric morbidity and mortality. However, multiple conditions remain genetically and/or pathophysiologically unexplained.

Positive genetic findings in patients continue to contribute in a significant way towards elucidating the specific pathophysiological mechanisms of disease in complex phenotypes and clarifying genotype - phenotype relationships. Consanguineous families have especially played a role in the discovery of novel genes.

\section{Consanguinity}

"Consanguinity" or "inbreeding" in population genetics refers to non-random mating where humans mate with others who are more genetically similar, rather than mating at random in the population. Consanguinity is linked to demographic, cultural, and religious practises [3]. These practises served many purposes from ancient times, and are more common in some areas around the world than others, especially in Asia, Africa, and the Middle-East [3]. In modern times, despite increased awareness on the possible health consequences for children of consanguineous families, it has been estimated that over $20 \%$ of the world population live in communities which prefer such marriages and that over $8.5 \%$ of all children worldwide have consanguineous parents [4].

In a large genetic study performed in Egypt, recessive disorders were found mainly among families with consanguinity (78.8\%). Consanguinity was present in $100 \%$ of cases of mental retardation and in $92.6 \%$ of patients with limb anomalies. Child deaths and stillbirths were more prevalent among children from consanguineous parents when compared to non-consanguineous families as well [4].

The higher frequency of recessive genetic conditions in descendants of consanguineous parents than those of unrelated parents can be attributed to less common alleles manifesting as homozygous. For example, first cousins are predicted to share $1 / 8$ th of their genes. Therefore, their progeny will be homozygous (or autozygous) at $1 / 16$ th of gene loci. In other words, this means that they will have identical gene copies from each parent at these sites in their genome; these are called "runs of homozygosity" [5]. Thereby, consanguinity represents a substantial genetic burden for the offspring.

If a variant with a heterozygosity frequency of 1 in 100 is considered, there is a 1 in 10,000 chance that both unrelated spouses are carriers $(1 / 100 \times 1 / 100=1 / 10,000)$. However, if they are first cousins, the chance of both being carriers of this pathogenic variant is 12.5 times higher, thereby the chance is 1 in $800(1 / 100 \times 1 / 8=1 / 800)$. In families with multiple consanguinity, this risk would be even higher [6].

Thus, when a rare and complex monogenic condition is suspected, consanguineous families provide the best chances for novel gene discovery. This has been proven over time in scientific research, even in research into paediatric endocrine disorders, which will be elaborated in the individual sections below.

\section{Genetic Testing Methods}

Karyotype testing was the only available method for identifying genetic defects until the 1970s. It was possible to identify chromosome aberrations and other structural abnormalities (major translocations, deletions, and inversions) using karyotyping [7]. In 1977, Sanger et al. [8] first described the basic concepts of DNA sequencing as a method to detect point mutations and with the growing popularity of polymerase chain reaction, and this method was widely used allowing amplification of a targeted region of DNA. Sanger sequencing still remains the gold standard for identification of mutations, using the "candidate gene approach" in situations where a specific gene is suspected based on the patient phenotype [7].

In the 1990s, methods of fluorescent in situ hybridization, array comparative genomic hybridization, and linkage analysis were developed. These techniques lead to the discovery of many novel genes, though limited to the detection of large copy number variants [7].

The successful sequencing of the entire human genome in 2001 led to a boom of genetic testing techniques including NGS over the last 2 decades [7]. NGS methods (the present standard when genetically examining patients with complex phenotypes) have unified all abovementioned methods and provide a way to detect all mutation types - single nucleotide variants, insertions or deletions, 
Table 1. Overview of genes mentioned in the manuscript (in the order of mention) and the role of consanguinity in their discovery

\begin{tabular}{|c|c|c|c|c|c|}
\hline Gene & Condition caused & First published & Method used for gene discovery & Role of consanguinity & Ref \\
\hline$A B C C 8$ & $\mathrm{CHI}$, neonatal diabetes & 1995 & FISH, direct Sanger sequencing & $\begin{array}{l}\text { By testing affected individuals from } 9 \\
\text { consanguineous families }\end{array}$ & [19] \\
\hline KCNJ11 & $\mathrm{CHI}$, neonatal diabetes & 1996 & Direct Sanger sequencing & $\begin{array}{l}\text { By testing } 1 \text { affected individual from a } \\
\text { consanguineous family }\end{array}$ & {$[20]$} \\
\hline PTF1A & Neonatal diabetes & 2003 & Genome-wide linkage analysis & $\begin{array}{l}\text { By testing } 3 \text { affected individuals from a } \\
\text { consanguineous family }\end{array}$ & [26] \\
\hline WFS1 & Syndromic/neonatal diabetes & 1998 & Genetic linkage analysis & $\begin{array}{l}\text { One of } 5 \text { tested families was } \\
\text { consanguineous }\end{array}$ & [29] \\
\hline EIF2AK3 & Syndromic/neonatal diabetes & 2000 & Genome-wide linkage analysis & $\begin{array}{l}\text { By testing done in } 2 \text { affected } \\
\text { consanguineous children }\end{array}$ & [30] \\
\hline$\angle R B A$ & $\begin{array}{l}\text { Autoimmune monogenic } \\
\text { diabetes }\end{array}$ & 2012 & Genetic linkage analysis & $\begin{array}{l}\text { By studying } 5 \text { affected individuals from } 4 \\
\text { consanguineous families }\end{array}$ & [38] \\
\hline GHR & Short stature & 1989 & Genetic linkage analysis & $\begin{array}{l}\text { By studying affected children from } 2 \\
\text { consanguineous families }\end{array}$ & [42] \\
\hline GH1 & Short stature & 1981 & $\begin{array}{l}\text { Restriction endonuclease } \\
\text { analysis }\end{array}$ & $\begin{array}{l}\text { By studying } 2 \text { siblings from first-cousin } \\
\text { parents }\end{array}$ & [46] \\
\hline GHRHR & Short stature & 1996 & Direct Sanger sequencing & $\begin{array}{l}\text { By testing several severe affected } \\
\text { members of a consanguineous family }\end{array}$ & [47] \\
\hline POU1F1 & Short stature & 1992 & Direct Sanger sequencing & $\begin{array}{l}\text { By testing an affected child from } 1 \\
\text { consanguineous family }\end{array}$ & [50] \\
\hline
\end{tabular}

RT, reverse transcriptase; PCR, Polymerase Chain Reaction; WGS, Whole Genome Sequencing; WES, Whole Exome Sequencing; FISH, fluorescent in situ hybridization.

structural variants, and copy number variants. However, a vital factor is the selection of the library to be adopted (due to cost and interpretation of results) [9]. The library refers to the extent of the human genome which is examined, and some types of libraries are custom-targeted panels (t-NGS), whole-exome sequencing (WES - which is focused on the $1 \%$ protein coding region of the genome), or whole-genome sequencing. T-NGS is a suitable, affordable tool to analyse many patients with a specific diagnosis (which is caused by a known group of genes) if a suitable gene panel has been created and tested [9].

The data obtained by NGS methods need to be analysed by a process called a bioinformatics pipeline [7]. Technical advancements have facilitated the storage and rapid exchange of these data, allowing more efficient analysis (using bioinformatics software capable of gathering comprehensive information about a single variant), consulting of variants, and international collaboration [7, 9]. The gold standard in variant classification is the American College of Medical Genetics and Genomics (ACMG) guidelines, which classifies possible variants in a range from benign to pathogenic [10]. Pathogenic variants are confirmed by Sanger sequencing [8].

Genetic testing methods used in consanguineous families are not largely different from methods used in nonconsanguineous families. It is important to note the higher percentage of "runs of homozygosity" in consanguineous individuals and the importance of using homozygous 
markers (homozygosity mapping) to discover the true genetic cause, especially when having many variants of unknown significance [11].

\section{Genetic Causes of Specific Disorders: Insight into the Role of Consanguinity}

In this review, we will focus on the 3 groups of paediatric endocrine conditions to highlight the contribution of consanguineous offspring to elucidate their genetic and pathophysiological background (Table 1). These conditions are representative of gradients of pathophysiological complexity, congenital hyperinsulinism (CHI) (a "single cell condition") being the most straightforward and short stature the most complex. We believe that highlighting the evolution of genetic knowledge in these 3 conditions will provide an overall picture, shared by almost all paediatric endocrine disorders. It is important to note that this review does not include all genes that were discovered with the help of consanguinity; the genes mentioned in detail under each condition were selected due to their prominence and frequency in literature.

\section{Congenital Hyperinsulinism}

$\mathrm{CHI}$ is a heterogeneous genetic condition caused by a primary genetic defect of the pancreatic $\beta$-cell resulting in uncontrolled insulin secretion. The incidence of $\mathrm{CHI}$ has been estimated to be around 1:2,500 in communities with a higher rate of consanguinity, whereas it is $1: 50,000$ in non-consanguineous populations [12]. Similar to some other conditions, it has been clearly shown that not only the incidence and genetic causes of $\mathrm{CHI}$, but also the mode of inheritance differs crucially between high- and low-consanguineous areas, with recessive (biallelic) transmission prevailing in high-consanguineous, and monoallelic (dominant/uniparental isodisomy) transmission prevailing in low-consanguineous areas [13]. In $\mathrm{CHI}$, the mode of inheritance directly impacts disease severity, for example, recessive biallelic variants mostly cause (more severe) diffuse $\mathrm{CHI}$ and paternally inherited monoallelic variants cause focal $\mathrm{CHI}$, where complete surgical resection of the lesion can be curative [14].

The pancreatic $\beta$-cell has the capability to detect the current blood glucose concentration and to produce, store, and release insulin to the bloodstream to maintain a normal blood glucose concentration without the risk of hypoglycaemia [15]. The pathophysiology of $\mathrm{CHI}$ is mostly based around genetic defects of $\beta$-cell function (shown in Fig. 1). Genetic testing in children with $\mathrm{CHI}$ is crucial for confirming diagnosis and tailoring therapy; it may play an important role in genetic counselling, or to explain fatal outcomes in previous offspring [16].

The 2 most common genes known to cause $\mathrm{CHI}$ are $A B C C 8$ and KCNJ11 (encoding the SUR1 and Kir6.2 subunits of the ATP-sensitive $\mathrm{K}+\left[K_{\mathrm{ATP}}\right]$ channel in the pancreatic $\beta$-cell). Pathogenic variants in these genes cause the most severe forms of $\mathrm{CHI}$, due to the loss of $K_{\mathrm{ATP}}$ channel activity, persistent membrane depolarization, and continuous insulin release, regardless of the blood glucose concentration [17].

Linkage analysis studies done by Glasser et al. [18] in 1994 in 15 families lead to CHI being mapped to chromosome 11p14-15.1. This confirmed the existence of a Mendelian disease locus for the condition [18]. Twelve were Ashkenazi Jewish families (most came from areas where marriage between second and third cousins was common), and 2 were Arabic (with confirmed consanguinity). In 1995, Thomas et al. [19] mapped SUR to chromosome $11 \mathrm{p} 15.1$ by using fluorescent in situ hybridization. By testing affected individuals from 9 consanguineous families, he identified 2 SUR gene splice site mutations, which segregated with disease, thereby confirming the existence of the $A B C C 8$ gene. This signified the start of a deeper understanding into the pathophysiological relationship of the pancreatic $\beta$-cell function with $K_{\mathrm{ATP}}$ channel proteins in CHI.

In 1996, Tomas et al. [20] considered Kir6.2 as another candidate gene for $\mathrm{CHI}$ because of its close location to the SUR gene and its necessity for the functioning of the $\beta$-cell $K_{\text {ATP }}$ channel. They found a homozygous missense variant in a child with $\mathrm{CHI}$ from a consanguineous family, confirming that variants in gene Kir6.2, currently called KCNJ11, cause CHI as well.

At the point of writing this article, pathogenic variants causing $\mathrm{CHI}$ have been found in over 15 genes including GLUD1, GCK, HNF4A, and HNF1A (shown in Fig. 1) [16]. In addition, some genetic syndromes in non-consanguineous populations such as Beckwith-Wiedemann, Kabuki, and Turner syndromes have been associated with hyperinsulinism as well $[17,21]$.

\section{Diabetes Mellitus}

Diabetes mellitus (DM) is a group of conditions that result from an absolute or relative insulin deficiency, with or without insulin resistance, which leads to hyperglycae- 
Fig. 1. Functional components of the pancreatic $\beta$-cell and the molecular pathophysiology of CHI. Cellular locations of proteins encoded by genes causative for $\mathrm{CHI}$ are assigned the following numbers: 1 KCNJ11, 2 - ABCC8, 3 - GLUD1, 4 HADH1, 5 - GCK, 6 - PGM1, 7 - HK1, 8 - HNF4A, 9 - HNF1A, 10 - UCP2, 11 PMM2, 12 - FOXA2, 13 - CACNA1D, $14-S L C 16 A 1$.

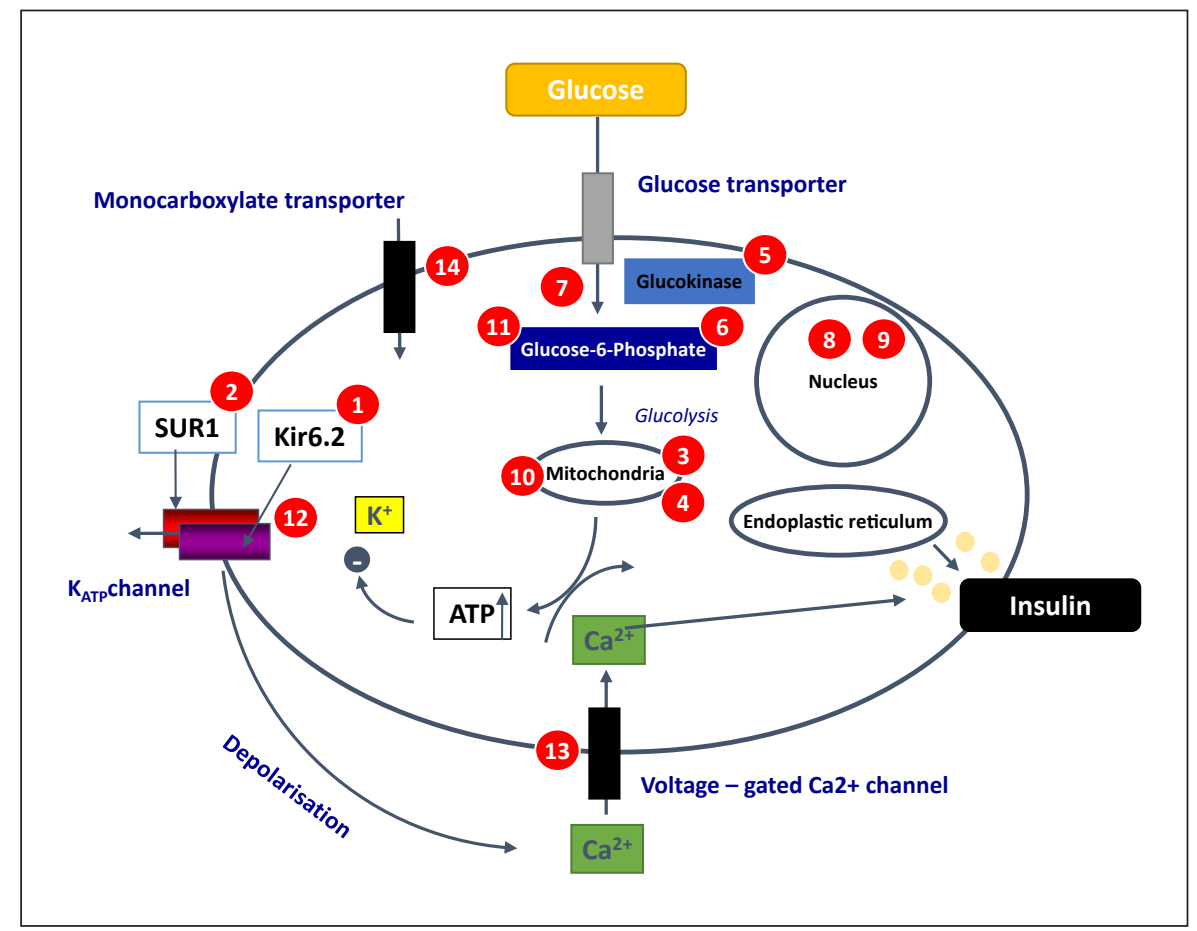

mia and glycosuria. In addition to type $1 \mathrm{DM}$ and type 2 $\mathrm{DM}$, which are polygenic diseases with significant environmental components, the less frequent monogenic forms of diabetes continue to help uncover various biological processes causing diabetes due to insufficient insulin production or defects in insulin action [22].

Monogenic diabetes comprises of partially overlapping subtypes, such as neonatal DM (NDM), syndromic diabetes, autoimmune monogenic diabetes, and maturity-onset diabetes of the young. Maturity-onset diabetes of the young follows a pattern of autosomal dominant inheritance while syndromic diabetes is almost exclusively recessive, and NDM and autoimmune monogenic diabetes show both forms of inheritance [23]. The prevalence of monogenic diabetes in the UK paediatric diabetic population was $2.5 \%$ in a 2016 study examining 808 patients with positive urinary C-peptide creatinine ratio and negative islet cell-antibodies [23]. A similar Italian study showed a prevalence of $6.5 \%$ [24].

However, even though such studies have not yet been carried out in a population with prevalent consanguinity, it has been clearly shown that (among children with permanent NDM) the spectrum of genetic aetiologies differs largely between areas with high and low rates of consanguinity (shown in Fig. 2). In consanguineous regions, the most common gene was EIF2AK3 causing Wolcott-Ral-

Consanguinity and Its Impact on

Paediatric Endocrine Research lison syndrome and genes $K C N J 11$ and $A B C C 8$ accounted only for $12 \%$ of cases, whereas in the non-consanguineous areas - these 2 genes prevailed (46\%). Predictably, there was a much higher incidence of recessive forms of permanent NDM ( $81 \%$ of recessive findings were from consanguineous offspring vs. $13 \%$ in non-consanguineous offspring) [25].

NDM (diabetes which develops before 6 months of age) is caused by single-gene mutations (in genes such as ABCC8, KCNJ11, GCK, PDX1, INS, GATA6, NEUROG3, etc.) which reduce pancreatic $\beta$ cell number or impact its' function [24] (shown in Fig. 2, 3). Many genes such as PTF1A were discovered due to genetic testing on consanguineous families [26]. In 2020, Franco et al. [27] identified the first gene (YIPF5) to cause NDM by increased endoplasmic reticulum (ER) stress caused by the disruption of ER-to-Golgi trafficking in the $\beta$-cell. YIPF5 was described in 6 consanguineous children with NDM, microcephaly, and epilepsy. This helped further highlight the overlap in genes (such as CNOT1) crucial for the development and functioning of both $\beta$ cells and neurons [27].

Monogenic syndromic diabetes is typically characterized by the negativity of beta-cell autoantibodies and additional (typically non-autoimmune) phenotypic abnormalities. In 1977, children with diabetes insipidus, DM, 
Fig. 2. Spectrum of genes causing permanent neonatal diabetes in patients born to non-consanguineous parents in comparison with children born to consanguineous parents (diagram adapted from reference [24]).

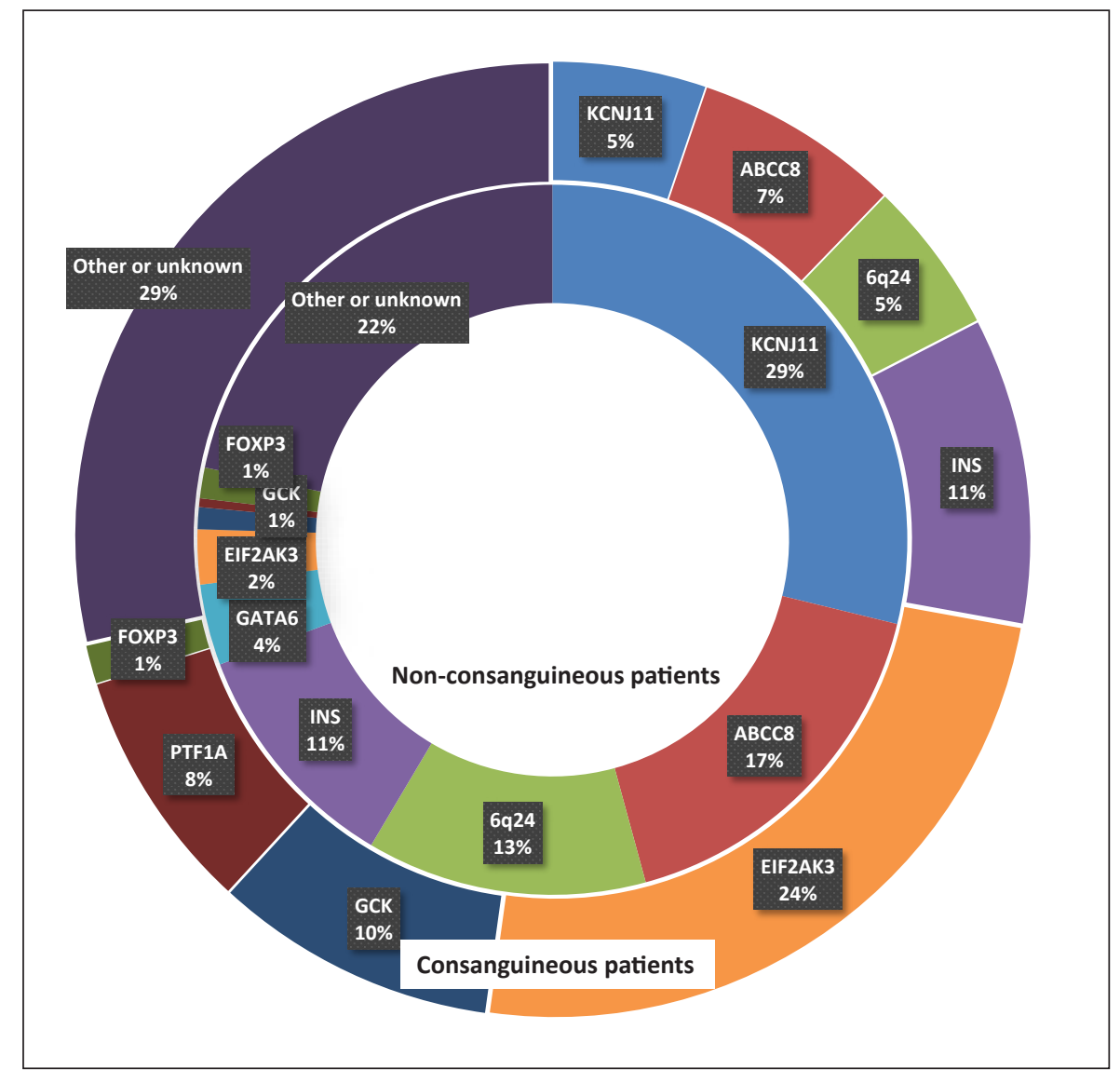

optic atrophy, and deafness (DIDMOAD, later called Wolfram syndrome) were observed, particularly in consanguineous families with healthy parents and siblings, suggesting a condition with autosomal recessive inheritance [28]. It was later mapped due to homozygous mutations in gene WFS1-encoding wolframin (an ER protein involved in the regulation of the response to ER stress) [29]. Testing in 2 consanguineous families led to gene discovery (EIF2AK3 - an ER protein which is a key ER stress transducer) in previously mentioned Wolcott-Rallison syndrome which causes PNDM [30].

Another example is recessively inherited thiamine-responsive megaloblastic anaemia causing megaloblastic anaemia, DM, and sensorineural deafness. This was mapped to gene SLC19A2 in 1999 by testing in 6 families, 3 reported a history of consanguinity; however, they were all shown to be linked to a gene region based on homozygous markers, suggesting linkage disequilibrium and the existence of a founder mutation [31].

Autoimmune monogenic diabetes represents an overlap between classical T1DM and syndromic monogenic diabetes, and typically manifests at an early age. Two monogenic syndromes of polyglandular autoimmunity were genetically elucidated more than 20 years ago: the autoimmune polyendocrinopathy-candidiasis-ectodermal dystrophy syndrome and the X-linked (IPEX) syndrome caused by variants in the AIRE and FOXP3 genes, respectively $[32,33]$. These are rare diseases but, for example, the autoimmune polyendocrinopathy-candidiasis-ectodermal dystrophy syndrome has been detected at high rates among certain populations such as the Finnish $(1: 25,000)$, Sardinian $(1: 14,000)$, and Iranian Jewish $(1: 6,500-1: 9,000)$ as a result of founder mutations [34, 35]. The higher frequency in Iranian Jews can be additionally attributed to the presence of consanguinity in this population. Since then, multiple other genes responsible for autoimmune monogenic diabetes have been described (shown in Fig. 3) [36]. These genes can be divided further into genes causing autosomal recessive forms of autoimmune monogenic diabetes (IL2RA and $L R B A$ ), X-linked recessive forms (FOXP3), dominant forms (CTLA4 and STAT3), and genes that can be inherited both ways (AIRE) 


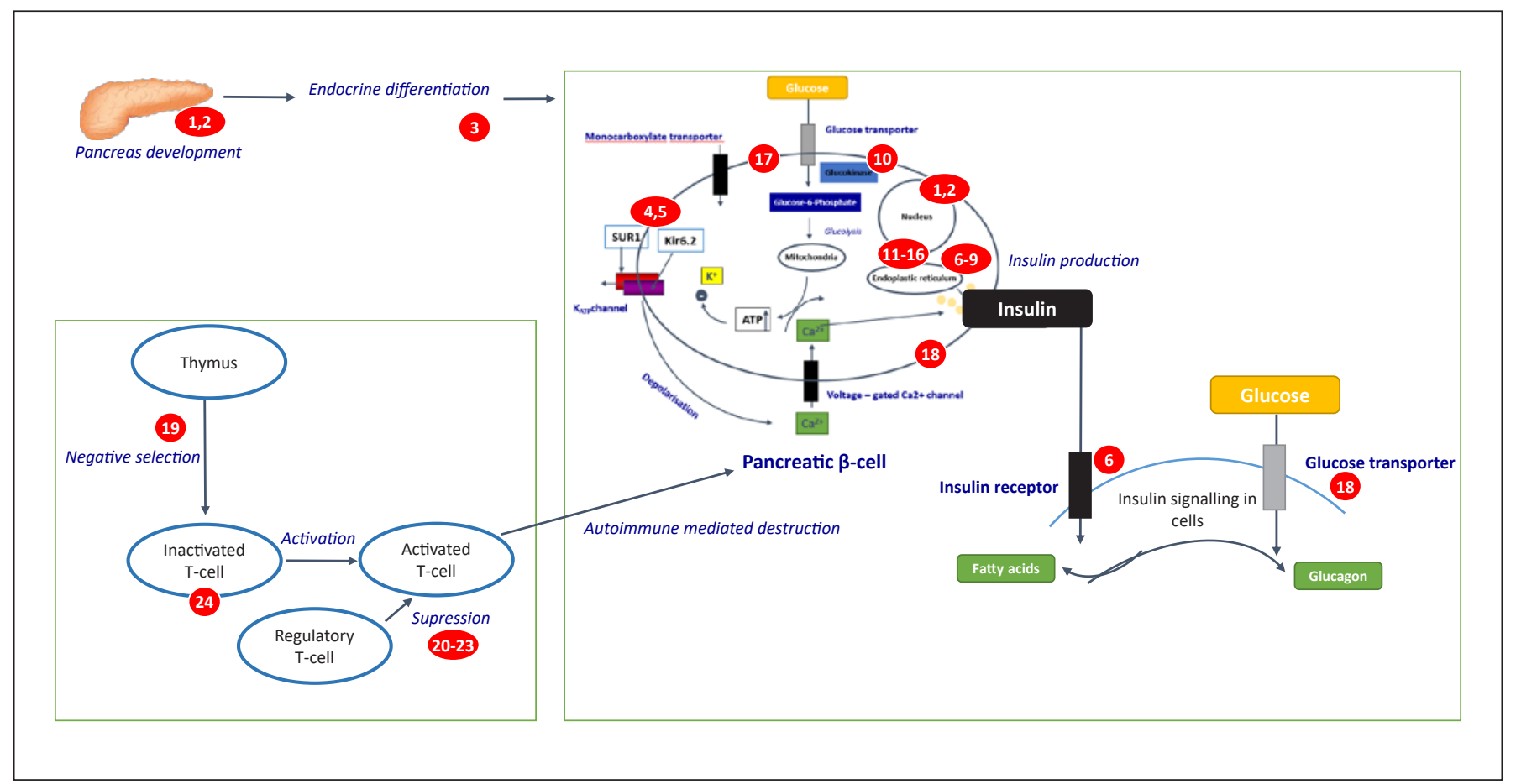

Fig. 3. Overview of the molecular pathophysiology of monogenic diabetes. Functional locations of proteins encoded by causative genes (mentioned in the manuscript) are assigned the following numbers: $1-P D X 1,2-$ CNOT1 (pancreas development genes), 3 - NEUROG3 (an endocrine differentiation gene), 4 - ABCC8, 5 KCNJ11 (K $\mathrm{K}_{\text {ATP }}$ channel genes), 6 - INS, 7 - EIF2AK3, 8 - WFS1, 9 - YIPF5 (insulin and ER genes), 10 - GCK (glucokinase gene), 11 - HNF4A, 12 - HNF1A, 13 - HNF1B, 14 - PTF1A, 15 - FOXP3, 16 - GATA6 (transcription factor genes present in the nucleus), 17 - SLC19A2, 18 - GLUT1 (transporter genes), 19 - AIRE, 20 - FOXP3, 21 - IL2RA, 22 - LRBA, 23 - CTLA4, 24 - STAT3 (immune regulating genes).

(shown in Fig. 3) [36]. Consanguinity played a role in the discovery of IL2RA (found in a boy from a first-cousin marriage with an immunodeficiency syndrome) and $L R B A$ (due to genetic linkage analysis carried out in consanguineous families with hypogammaglobulinemia) $[37,38]$.

\section{Growth Regulation Disorders/Short Stature}

Many different genes impact growth by various mechanisms. The hypothalamic-pituitary axis of growth hormone $(\mathrm{GH})$ and insulin-like growth factor (IGF)-1 was long believed to be the main linear growth regulator in children. However, recent studies have shown that it is rather regulated by 2 major tiered pathways - the GHIGF-1 axis and the complex regulation of growth plate chondrocytes and the extracellular cartilaginous matrix (shown in Fig. 4) [39, 40].

Consanguinity and Its Impact on

Paediatric Endocrine Research

\section{GH-IGF-1 Axis}

Mutations in genes regulating steps in the entire $\mathrm{GH}$ IGF-1 axis, ranging from GH deficiency (GHD), primary IGF-1 deficiency to IGF-1 resistance may cause short stature. The first genetic syndrome related to this axis was clinically described by Laron et al. [41] in 1966. It was characterized by severe growth retardation, obesity, and small genitalia in 3 siblings from a consanguineous Jewish family and was later named Laron syndrome [41]. It was characterized by high serum GH concentrations and low to undetectable IGF-1 concentrations. In patients with this rare syndrome, $\mathrm{GH}$ resistance was demonstrated by the administration of exogenous human GH for 7 days, which did not lead to IGF-1 increase [42]. Later, in 1984, Eshet et al. [43] proved that the mechanism of GH resistance is due to an inability of GH to bind to the respective receptor. Soon thereafter, in 1989, the GH receptor gene was described as causative by Amselem et al. [42], by using gene linkage methods in 2 consanguineous families from the Mediterranean region.

Horm Res Paediatr 2022;95:1-11 DOI: $10.1159 / 000521210$ 
Fig. 4. Overview of the molecular pathophysiology of short stature due to genetic defects in the GH-IGF-1 axis and the growth plate. Functional locations of proteins encoded by causative genes (mentioned in the manuscript) are assigned the following numbers: 1 - POU1F1, 2 - PROP1, 3 - GLI2, 4 - FGF8, 5 - HESX1, 6 - SOX2, 7 - SOX3, 8 - FOXA2 (pituitary transcription factors), 9 - GH1, 10 - GHRHR, 11 - GHR, 12 - PAPPA2, 13 - IGF-1R, 14 - ALS (other genes causing short stature by affecting the $\mathrm{GH}$ IGF-1 axis), 15-COL1A2, 16 - COL2A1, 17 - COL11A1, 18 - FBN1, 19 - MATN3 (extracellular matrix genes), $20-N P R 2$ (paracrine signalling gene), 21 - SHOX (gene involved in intracellular pathways), 22 - PCNT (gene involved in cell division and DNA replication/repair).

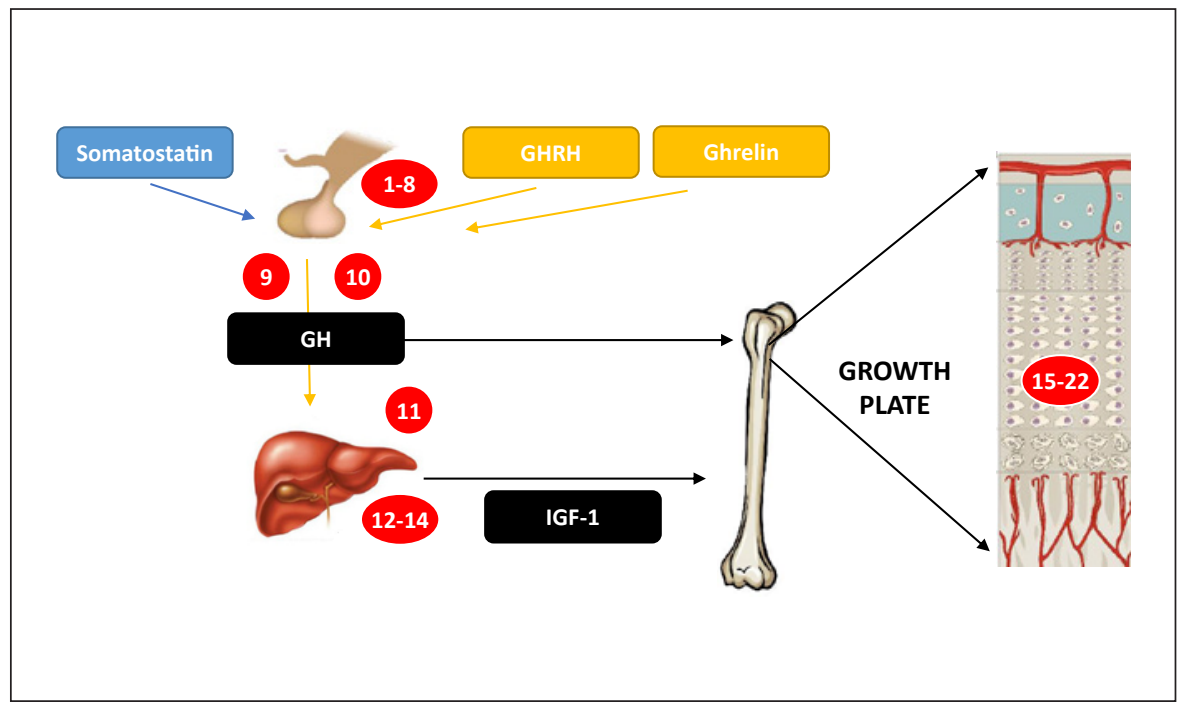

During this time, the genetic transmission of severe isolated GH deficiency (IGHD) was studied as well. This occurs with an incidence of between 1 in 4,000 and 1 in 10,000 live births [44]. Classical genetic causes of IGHD include mutations of the gene-encoding GH (GH1) and the $\mathrm{GH}$ releasing hormone receptor (GHRHR). Thus far, there have been no instances of GHD as a result of mutations in GH releasing hormone $(G H R H)$ itself [44].

Historically, genetic forms of IGHD were classified into 4 types, depending on the inheritance pattern, as autosomal recessive (types IA and IB), dominant (type II), or X-linked (type III) [45]. This classification no longer applies due to expanding knowledge into the pathophysiology of GHD. Autosomal recessive IGHD type IA was first described in patients with homozygous GH1 deletions, including 2 siblings from Italian first-cousin parents having IGHD due to a $7.6 \mathrm{~kb}$ deletion in the $\mathrm{GH}$ gene cluster [46]. Patients present with severe growth failure by 6 months of age with undetectable GH concentrations. Some of these children tend to develop antibodies on treatment, thereby resulting in poor response to GH therapy [46].

Subsequently, the first homozygous loss-of-function GHRHR mutation causing profound IGHD was described in 2 patients from a consanguineous Indian family with extreme short stature, frontal bossing, truncal obesity, and severe GHD. These siblings failed to respond to neither GH stimulation tests nor repetitive GHRH stimulation [47]. This was followed by the description of the "dwarfs of Sindh" a cluster of consanguineous patients from Sindh, Pakistan, with severe GHD and
GHRHR mutations which results in the inability to transmit the GHRH signal [48].

Short stature can be caused by conditions causing combined pituitary hormone deficiencies as well. Pituitary development is governed by the activation of a cascade of transcription factors that orchestrate pituitary morphogenesis and differentiation. Thereby, defects in pituitary transcription factor genes such as POU1F1, PROP1, GLI2, FGF8, HESX1, SOX2, SOX3, FOXA2, and others been found to lead to varying degrees of combined pituitary hormone deficiencies [44, 49].

The first gene which was shown to cause multiple pituitary hormone deficiency in humans was POU1F1 (originally PIT1). A biallelic pathogenic variant was described in 1992 in 2 sisters from a consanguineous family with a clinical presentation suggestive of cretinism. Hormonal workup showed profound deficiencies of thyroidstimulating hormone, $\mathrm{GH}$, and prolactin. These patients were the first described case of a defect of a transcriptional activator causing deficiency of multiple target genes [50].

Recently, 2 families (one of which was consanguineous) with children with progressive postnatal growth failure and markedly elevated serum concentrations of IGF-1, IGF-binding proteins (IGFBP)3, IGFBP5, acid labile subunit, and IGF-2 concentrations were reported. This was shown to be resulting from homozygous loss of function of the PAPPA2 gene, which leads to low IGF1 bioavailability. This indicates that PAPPA2 is a key regulator of IGF-1 bioavailability by regulating the proportion of IGF-1 that is bound to IGF-binding proteins [51]. 
Growth Plate Chondrocytes and Extracellular Matrix

Disorders of chondrocyte paracrine regulation (for example, NPR2 defects), defects in intracellular pathways such as "RASopathies" or mutations in transcriptional factor genes (for example, SHOX) cause short stature as well $[40,44,52,53]$. Homozygous inactivating mutations in NPR2 cause severe acromesomelic Maroteaux dysplasia and was first described in 2004 via testing done in a predominantly consanguineous cohort [54].

Impairment of DNA repair can result in rare autosomal recessive forms of very severe short stature (such as microcephalic osteodysplastic primordial dwarfism type II - birth weight typically $<1,500 \mathrm{~g}$ at term and an adult height of $<100 \mathrm{~cm}$ ). One example is the gene PCNT which encodes pericentrin (a centrosomal protein) first discovered by linkage analysis studies in 2 consanguineous families [55].

Extracellular matrix structure genes including collagen regulating genes such as COL1A2, COL2A1, COL$11 A 1$, fibrillin genes such as $F B N 1$ and matrilin genes such as MATN3 impact growth as well $[52,56]$. These gene mutations most often cause milder forms of short stature in heterozygous form and more severe forms in homozygous/recessive form. Consanguineous families have helped extend the disease phenotype and genotypephenotype relationship such as in the case of gene MATN3 where a novel form of autosomal recessive spondylo-epimetaphyseal dysplasia caused by homozygous MATN3 mutations was described in a large consanguineous family with 5 affected individuals [57].

\section{Conclusion}

The presence of consanguinity in families with children with endocrine disease represents a substantial genetic burden for the offspring due to the higher probabil- ity of a single-gene condition with autosomal recessive inheritance. Not all pathogenic genes in the above-mentioned conditions were discovered with the help of related marriages; however, consanguineous families have been invaluable in elucidating novel genes and novel mechanisms of disease despite this genetic burden. Thus, it can be said that genetic examination in consanguineous families could trigger novel advancements in pathophysiological research and extend medical knowledge. Therefore, continued genetic testing (specially using methods such as whole-genome sequencing) in areas with prevalent consanguinity could further help shed light on conditions where the genetic background and pathophysiology are not fully known.

\section{Conflict of Interest Statement}

The authors have no conflicts of interest to declare.

\section{Funding Sources}

Author's research is supported by the Charles University Grant Agency (GA-UK grant number 340420) and by A.Z.V. grant agency, Ministry of Health, Czech Republic (Grants NV18-01-00078 and NV18-07-00283).

\section{Author Contributions}

J.L. designed this review. S.A.A. wrote the manuscript. T.H.T. and P.D. provided insight into genetic findings and testing in consanguineous areas. S.A.A. and J.L. prepared the figures. S.P. and J.L. revised the manuscript critically. All authors contributed to the discussion, reviewed or edited the manuscript, and approved the final version to be published.

\section{References}

1 Baird PA, Anderson TW, Newcombe HB, Lowry RB. Genetic disorders in children and young adults: a population study. Am J Hum Genet. 1988;42(5):677-93.

2 Eggermann T, Elbracht M, Kurth I, Juul A, Johannsen TH, Netchine I, et al. Genetic testing in inherited endocrine disorders: joint position paper of the European reference network on rare endocrine conditions (EndoERN). Orphanet J Rare Dis. 2020;15(1):144.

3 Bittles A. Consanguinity and its relevance to clinical genetics. Clin Genet. 2001;60(2):8998.

Consanguinity and Its Impact on

Paediatric Endocrine Research
4 Shawky RM, Elsayed SM, Zaki ME, El-Din SMN, Kamal FM. Consanguinity and its relevance to clinical genetics. Egypt J Med Hum Genet. 2013;14(2):157-64.

5 Bennett RL, Motulsky AG, Bittles A, Hudgins L, Uhrich S, Doyle DL, et al. Genetic counseling and screening of consanguineous couples and their offspring: recommendations of the national society of genetic counselors. J Genet Couns. 2002;11(2):97-119.

6 Antonarakis SE. Carrier screening for recessive disorders. Nat Rev Genet. 2019;20(9): $549-61$.
7 Tenore A, Driul D. Genomics in pediatric endocrinology-genetic disorders and new techniques. Pediatr Clin North Am. 2011;58(5): 1061-ix.

8 Sanger F, Nicklen S, Coulson AR. DNA sequencing with chain-terminating inhibitors. Proc Natl Acad Sci USA. 1977;74(12):5463-7.

9 Persani L, de Filippis T, Colombo C, Gentilini D. Genetics in endocrinology: genetic diagnosis of endocrine diseases by NGS: novel scenarios and unpredictable results and risks. Eur J Endocrinol. 2018;179(3):R111-23. 
10 Richards S, Aziz N, Bale S, Bick D, Das S, Gastier-Foster J, et al. Standards and guidelines for the interpretation of sequence variants: a joint consensus recommendation of the American college of medical genetics and genomics and the association for molecular pathology. Genet Med. 2015;17(5):405-24.

11 Wakeling MN, Laver TW, Wright CF, De Franco E, Stals KL, Patch AM, et al. Homozygosity mapping provides supporting evidence of pathogenicity in recessive Mendelian disease. Genet Med. 2019;21(4):982-6.

12 Mathew PM, Young JM, Abu-Osba YK, Mulhern BD, Hammoudi S, Hamdan JA, et al. Persistent neonatal hyperinsulinism. Clin Pediatr. 1988;27(3):148-51.

13 Rozenkova K, Malikova J, Nessa A, Dusatkova $L, B j ø r k h a u g ~ L, ~ O b e r m a n n o v a ~ B$, et al. High incidence of heterozygous ABCC 8 and HNF1A mutations in Czech patients with congenital hyperinsulinism. J Clin Endocrinol Metab. 2015;100(12):E1540-E1549.

14 Snider KE, Becker S, Boyajian L, Shyng SL, MacMullen C, Hughes N, et al. Genotype and phenotype correlations in 417 children with congenital hyperinsulinism. J Clin Endocrinol Metab. 2013;98(2):E355-363.

15 Shah P, Rahman SA, Demirbilek H, Güemes M, Hussain K. Hyperinsulinaemic hypoglycaemia in children and adults. Lancet Diabetes Endocrinol. 2017;5(9):729-42.

16 Amaratunga SA, Hussein Tayeb T, Rozenkova K, Kucerova P, Pruhova S, Lebl J. Congenital hyperinsulinism caused by novel homozygous KATP channel gene variants may be linked to unexplained neonatal deaths among kurdish consanguineous families. Horm Res Paediatr. 2020;93(1):58-65.

17 Stanley CA. Perspective on the genetics and diagnosis of congenital hyperinsulinism disorders. J Clin Endocrinol Metab. 2016;101(3): $815-26$.

18 Glaser B, Chiu KC, Anker R, Nestorowicz A, Landau H, Ben-Bassat H, et al. Familial hyperinsulinism maps to chromosome 11p14$15.1,30 \mathrm{cM}$ centromeric to the insulin gene. Nat Genet. 1994;7(2):185-8.

19 Thomas PM, Cote GJ, Wohllk N, Haddad B, Mathew PM, Rabl W, et al. Mutations in the sulfonylurea receptor gene in familial persistent hyperinsulinemic hypoglycemia of infancy. Science. 1995 Apr 21;268(5209):426-9.

20 Thomas P, Ye Y, Lightner E. Mutation of the pancreatic islet inward rectifier Kir6.2 also leads to familial persistent hyperinsulinemic hypoglycemia of infancy. Hum Mol Genet. 1996;5(11):1809-12.

21 Gibson CE, Boodhansingh KE, Li C, Conlin L, Chen P, Becker SA, et al. Congenital hyperinsulinism in infants with turner syndrome: possible association with monosomy $\mathrm{X}$ and KDM6A haploinsufficiency. Horm Res Paediatr. 2018 Jul;89(6):413-22.

22 Pociot F, Lernmark $\AA$. Genetic risk factors for type 1 diabetes. Lancet. 2016;387(10035): 2331-9.
23 Shepherd M, Shields B, Hammersley S, Hudson M, McDonald TJ, Colclough K, et al. Systematic population screening, using biomarkers and genetic testing, identifies $2.5 \%$ of the UK pediatric diabetes population with monogenic diabetes. Diabetes Care. 2016;39(11): 1879-88.

24 Delvecchio M, Mozzillo E, Salzano G, Iafusco D, Frontino G, Patera PI, et al. Monogenic diabetes accounts for $6.3 \%$ of cases referred to 15 Italian pediatric diabetes centers during 2007 to 2012. J Clin Endocrinol Metab. 2017; 102:1826-34.

25 De Franco E, Flanagan SE, Houghton JA, Lango Allen H, Mackay DJ, Temple IK, et al. The effect of early, comprehensive genomic testing on clinical care in neonatal diabetes: an international cohort study. Lancet. 2015; 386(9997):957-63.

26 Sellick GS, Garrett C, Houlston RS. A novel gene for neonatal diabetes maps to chromosome 10p12.1-p13. Diabetes. 2003;52(10): 2636-8.

27 De Franco E, Lytrivi M, Ibrahim H, Montaser $\mathrm{H}$, Wakeling MN, Fantuzzi F, et al. YIPF5 mutations cause neonatal diabetes and microcephaly through endoplasmic reticulum stress. J Clin Invest. 2020;130(12):6338-53.

28 Fraser FC, Gunn T. Diabetes mellitus, diabetes insipidus, and optic atrophy. An autosomal recessive syndrome? J Med Genet. 1977; 14(3):190-3.

29 Strom TM, Hörtnagel K, Hofmann S, Gekeler F, Scharfe C, Rabl W, et al. Diabetes insipidus, diabetes mellitus, optic atrophy and deafness (DIDMOAD) caused by mutations in a novel gene (wolframin) coding for a predicted transmembrane protein. Hum Mol Genet. 1998;7(13):2021-8.

30 Delépine M, Nicolino M, Barrett T, Golamaully M, Lathrop GM, Julier C. EIF2AK3, encoding translation initiation factor 2-alpha kinase 3 , is mutated in patients with WolcottRallison syndrome. Nat Genet. 2000;25(4): 406-9.

31 Labay V, Raz T, Baron D, Mandel H, Williams H, Barrett T, et al. Mutations in SLC19A2 cause thiamine-responsive megaloblastic anaemia associated with diabetes mellitus and deafness. Nat Genet. 1999;22(3):300-4.

32 Nagamine K, Peterson P, Scott HS, Kudoh J, Minoshima S, Heino M, et al. Positional cloning of the APECED gene. Nat Genet. 1997;17: 393-8.

33 Bennett CL, Christie J, Ramsdell F, Brunkow ME, Ferguson PJ, Whitesell L, et al. The immune dysregulation, polyendocrinopathy, enteropathy, X-linked syndrome (IPEX) is caused by mutations of FOXP3. Nat Genet. 2001;27:20-1.

34 Björses P, Aaltonen J, Vikman A, Perheentupa J, Ben-Zion G, Chiumello G, et al. Genetic homogeneity of autoimmune polyglandular disease type I. Am J Human Genet. 1996;59: 879-86.
35 Zlotogora J, Shapiro MS. Polyglandular autoimmune syndrome type I among Iranian Jews. J Med Genet. 1992;29:824-6.

36 Johnson MB, Cerosaletti K, Flanagan SE, Buckner JH. Genetic mechanisms highlight shared pathways for the pathogenesis of polygenic type I diabetes and monogenic autoimmune diabetes. Curr Diab Rep. 2019;19(5):20.

37 Sharfe N, Dadi HK, Shahar M, Roifman CM. Human immune disorder arising from mutation of the alpha chain of the interleukin-2 receptor. Proc Natl Acad Sci USA. 1997;94(7): 3168-71.

38 Lopez-Herrera G, Tampella G, Pan-Hammarström Q, Herholz P, Trujillo-Vargas CM, Phadwal $\mathrm{K}$, et al. Deleterious mutations in LRBA are associated with a syndrome of immune deficiency and autoimmunity. Am J Hum Genet. 2012;90(6):986-1001.

39 Wei X, Hu M, Mishina Y, Liu F. Developmental regulation of the growth plate and cranial synchondrosis. J Dent Res. 2016;95:1221-9.

40 Baron J, Sävendahl L, De Luca F, Dauber A, Phillip M, Wit JM, et al. Short and tall stature: a new paradigm emerges. Nat Rev Endocrinol. 2015;11(12):735-46.

41 Laron Z, Pertzelan A, Mannheimer S. Genetic pituitary dwarfism with high serum concentation of growth hormone: a new inborn error of metabolism? Isr J Med Sci. 1966;2:152-5.

42 Amselem S, Duquesnoy P, Attree O, Novelli G, Bousnina S, Postel-Vinay MC, et al. Laron dwarfism and mutations of the growth hormone-receptor gene. N Engl J Med. 1989;321: 989-95.

43 Eshet R, Laron Z, Pertzelan A, Arnon R, Dintzman M. Defect of human growth hormone receptors in the liver of two patients with Laron-type dwarfism. Isr J Med Sci. 1984;20(1):8-11.

44 Dauber A, Rosenfeld RG, Hirschhorn JN. Genetic evaluation of short stature. J Clin Endocrinol Metab. 2014;99:3080-92.

45 Mullis PE. Genetics of growth hormone deficiency. Endocrinol Metab Clin North Am. 2007;36(1):17-36.

46 Braga S, Phillips JA 3rd, Joss E, Schwarz H, Zuppinger K. Familial growth hormone deficiency resulting from a $7.6 \mathrm{~kb}$ deletion within the growth hormone gene cluster. Am J Med Genet. 1986;25(3):443-52.

47 Wajnrajch MP, Gertner JM, Harbison MD, Chua SC Jr, Leibel RL. Nonsense mutation in the human growth hormone-releasing hormone receptor causes growth failure analogous to the little (lit) mouse. Nat Genet. 1996; 12(1):88-90.

48 Baumann G, Maheshwari H. The dwarfs of sindh: severe growth hormone (GH) deficiency caused by a mutation in the GH-releasing hormone receptor gene. Acta Paediatr Suppl. 1997;423:33-8

49 Gregory LC, Dattani MT. The molecular basis of congenital hypopituitarism and related disorders. J Clin Endocrinol Metab. 2020;105(6): dgz184. 
50 Tatsumi K, Miyai K, Notomi T, Kaibe K, Amino N, Mizuno Y, et al. Cretinism with combined hormone deficiency caused by a mutation in the PIT1 gene. Nat Genet. 1992;1(1): 56-8.

51 Dauber A, Muñoz-Calvo MT, Barrios V, Domené HM, Kloverpris S, Serra-Juhé C, et al. Mutations in pregnancy-associated plasma protein A2 cause short stature due to low IGFI availability. EMBO Mol Med. 2016;8:363-74.

52 Jee YH, Andrade AC, Baron J, Nilsson O. Genetics of short stature. Endocrinol Metab Clin North Am. 2017;46(2):259-81.
53 Shears DJ, Vassal HJ, Goodman FR, Palmer RW, Reardon W, Superti-Furga A, et al. Mutation and deletion of the pseudoautosomal gene SHOX cause Leri-Weill dyschondrosteosis. Nat Genet. 1998;19(1):70-3.

54 Bartels CF, Bükülmez H, Padayatti P, Rhee DK, van Ravenswaaij-Arts C, Pauli RM, et al. Mutations in the transmembrane natriuretic peptide receptor NPR-B impair skeletal growth and cause acromesomelic dysplasia, type Maroteaux. Am J Hum Genet. 2004; 75(1):27-34.

55 Rauch A, Thiel CT, Schindler D, Wick U, Crow YJ, Ekici AB, et al. Mutations in the pericentrin (PCNT) gene cause primordial dwarfism. Science. 2008;319(5864):816-9.
56 Plachy L, Strakova V, Elblova L, Obermannova B, Kolouskova S, Snajderova M, et al. High prevalence of growth plate gene variants in children with familial short stature treated with GH. J Clin Endocrinol Metab. 2019; 104(10):4273-81.

57 Borochowitz ZU, Scheffer D, Adir V, Dagoneau N, Munnich A, Cormier-Daire V. Spondylo-epi-metaphyseal dysplasia (SEMD) matrilin 3 type: homozygote matrilin 3 mutation in a novel form of SEMD. J Med Genet. 2004;41(5):366-72. 